\title{
Influence of Plain, Twill, and Satin Weave Structures on the Optimum Colorfastness Properties of Reactive Dyes
}

\author{
Shariful Islam \\ Department of Textile Engineering, Faculty of Science and Engineering, City University, \\ Dhaka, Bangladesh
}

(Corresponding author's e-mail: shariful_bste@cityuniversity.edu.bd)

Received: 25 April 2020, Revised: 2 February 2021, Accepted: 30 July 2021

\begin{abstract}
The objective of this work is to study the influence of the plain, twill and satin weave structures on the colorfastness properties of reactive dyes. From the results, it can be concluded that plain weave fabric showed the optimum colorfastness properties due to its compact interlacement structure compared to twill and satin weave fabrics. Three types of plain, twill, and satin weave fabrics of different weave structures and weights $\left(\mathrm{g} / \mathrm{m}^{2}\right)$ were used in this research. The dyes, auxiliaries, and chemicals were applied, and the colorfastness tests were carried out in accordance with the test methods provided by ASTM and AATCC standards. Color strength $(\mathrm{K} / \mathrm{S})$ values were obtained using a reflectance spectrophotometer. A projection microscope was used to take cross sectional diagrams of the yarns for assessment. FTIR instrument transmitted infrared radiation to the dyed samples of up to a few microns to measure the spectroscopy within the visible spectral province with the maximum infrared ray (IR) peak values. The peak values of the FTIR device assured the presence of colorant or chromophore existing in the dyestuffs which were liable to expose the best colorfastness properties. This research is experimentally-based, and the findings are useful to personnel involved in cellulose fabric dyeing with reactive dyes and to the control of color properties. This research opens potential ways for scholars to advance study in this field.
\end{abstract}

Keywords: Colorfastness, Cellulose, Woven fabrics, Reactive dyes, Cover factor

\section{Introduction}

Textile industries are directly dependent on reactive dyes since they have good colorfastness properties. Reactive dyes provide bright and even color shades to textile materials [1]. They are very popular with customers and manufacturers all over the world for their sustainable characteristics. At the same time, these dyes are cheap and easily obtainable in the market [2]. Different specialists have investigated this topic at different intervals where a literature review exposed different outcomes. Some of these were identical to each other, but others were controversial. Eventually, if one standard was reformed during trialing, it led to a substantial change in research consequences. Colorfastness is the struggle of a substance to change in any of its color appearances, to the relocation of its colorants to neighboring ingredients, or both [3]. Fading is the color changing capabilities of the materials. Bleeding is the transmission of coloring components to an auxiliary attending fiber material [4]. Colorfastness properties, color intensity properties, and color strength characteristics are vital properties of textile materials [5]. It is the behavior of a color that authorizes it to hold its various features despite degradation through contact with sun light, heavy rain, crocking, or human body secretion [6].

The characteristics which can affect the color fastness properties of textile materials are fiber composition, yarn type, fabric construction, dyes, chemicals and auxiliaries, processing operations, and end use practices [7]. Dyes are mainly categorized consistent with their solubility properties and chemical characteristics. It is not possible to apply one dye to all types of fibers [8]. Dyes are classified according to their structures and interactions with fiber types and reactive groups [9]. Various binding forces sustain between the dyes and the materials. Reactive dyes are applicable for dyeing cotton fibers, whereas disperse dyes are suitable for dyeing polyester fibers [10]. Reactive dyes form covalent bonds in between the reactive group and the terminal $-\mathrm{OH}$ group of cellulosic fibers. These bonds are strong enough and establish very good colorfastness properties [11]. These dyes are so-called reactive dyes since they have reactive groups in their structure and react chemically with the fiber molecules to form covalent bonds 
between the reactive group and terminal $-\mathrm{OH}$ groups of cellulose fiber [12]. Covalent bonding is stronger than hydrogen bonding and ionic bonding; as a consequence, the reactive group turns into an integral part of the fiber molecules [13]. When fabric is submerged in dye solution, an electrolyte, such as $\mathrm{NaCl}$, is added to assist the exhaustion of dye, where it neutralizes the negative charges on the cellulose surface of cotton and helps absorption. The reactive group of the dye reacts with the terminal $-\mathrm{OH}$ groups of fiber molecules and forms a strong covalent bond. After dyeing, a series of hot, cold, and soap washings are required to remove the unfixed dye particles and excess chemicals to obtain good wash fastness properties [14].

The rate of reaction of the dye molecules with the fiber increases with increase in their reactivity [15]. Alternatively, if reactivity decreases, than the extent of hydrolysis also decreases, which results in slowing down its reaction with the fiber molecules [16]. The reactivity of reactive dye is also increased when the molecular weight of the reactive group increases [17]. These dyes are cationic types that can be used to dye cellulose, protein, and polyamide fibers [18]. These dyes are found in powder, liquid, and paste forms, and are strongly soluble in water. These dyes can show excellent colorfastness properties due to strong covalent bonds [19]. The reactive dyeing technique is cheap, easy, and requires less time/temperature to dye. They have a constant electron arrangement that can defend against degradation from ultraviolet rays [20]. Salt is used in a dye bath to increase the affinity of dye with fiber molecules. However, adding more salt in the dye bath decreases the hydrolysis process of the dyes [21]. This incidence neutralizes the electronegativity of the fiber surface if submerged in dye solution and increases dye absorption by generating additional energy to push the dye inside the fiber molecules [22].

People worldwide dye textile substances using available resources, but some dyestuffs generate bright and durable shades, such as purple and pink, which were much valued before the year 1850 as they were only obtained from a natural source of invertebrates" [23]. The dispersion dyeing technique is different from other dyeing processes because it follows the process of color trapping at high temperatures [24]. Shades of textile substances are dependent on the ability of an element to absorb light in the perceptible area of the electromagnetic array, which is from 380 to $700 \mathrm{~nm}$ [25]. Witt's theory clarified that colorants had two groups of chemicals; one is chromophore, which imparts color by absorbing light in the visible area, and the other is auxo-chrome, which helps to develop the color on materials [26]. This idea has been surpassed by the latest electronic construction principle of colors, by which dyestuffs are noticeable in a visible light range [27]. Color is an important term in textile wet processing, since it has extensive value for both the customers and manufacturers [28]. Holding original colors to textile materials is one of the vital quality parameters of colored textile products [29]. Maintaining the quality parameters of colored textile products is always a difficult challenge for textile manufacturers.

To attain desired colorfastness properties, a dyer must be aware of the requirements of the customer and act accordingly [30]. Dyestuffs, chemicals, auxiliaries, and process parameters extensively affect colorfastness properties. Dyeing temperature, bath $\mathrm{pH}$, time, machine speed, and dye concentrations are directly connected to the color properties of fabrics [31]. It is seen that synthetic fabrics have better colorfastness properties compared to cellulosic fabrics [32]. This is because polyester, or other synthetic fibers, can withstand more adverse conditions compared to cellulosic fibers [33]. This has been experimented on, such that reactive dyes exhibit excellent colorfastness properties when they are dyed with cellulosic fibers [34]. On the contrary, disperse dyes exhibit excellent color fastness properties when they are dyed with polyester or other synthetic fibers [35]. This research work was carried out to evaluate the effective colorfastness of reactive dyes on different cellulosic fabric structures.

\section{Materials and methods}

\section{Fabric type}

Cotton fabrics made of plain, twill, and satin weaves were used in this research for investigation, as shown in Table 1. They had similar densities for easy assessment and experimentation.

It is seen from the table that the number of picks per inch were 58,60 , and 62 , respectively, having the same number of ends in all cases. Therefore, the difference in weight was due to the extra 2 and 4 picks per inch in twill and satin, with reference to plain weave. In this table, warp yarn count is $20 \mathrm{Ne}$ and weft yarn count is $16 \mathrm{Ne}$. These fabrics had ends per inch (EPI) of 110 yarns and picks per inch (PPI) of 58, 60, and 62 yarns. All the fabrics had the same width of 59 inches with different weights. Figure 1 shows the structural diagram of plain, twill, and satin weave fabric [36]. 
Table $1100 \%$ Cotton cellulosic fabrics.

\begin{tabular}{cccccc}
\hline S.N & Composition & Construction & Weave & Weight $\left(\mathbf{g} / \mathbf{m}^{2}\right)$ & Width (") \\
\hline A & $100 \%$ Cotton & $\frac{20 \times 16}{110 \times 58}$ & $\frac{1}{1}$ plain & 235 & 59 \\
B & $100 \%$ Cotton & $\frac{20 \times 16}{110 \times 60}$ & $\frac{2}{1}$ twill & 237 & 59 \\
C & $100 \%$ Cotton & $\frac{20 \times 16}{110 \times 62}$ & $\frac{4}{1}$ satin & 240 & 59 \\
\hline
\end{tabular}
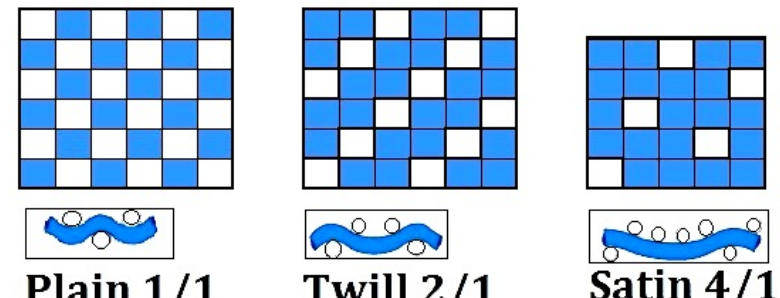

Plain 1/1

Twill 2/1

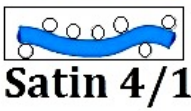

Figure 1 Structural diagram of plain, twill, and satin weaves.

\section{Dye type (reactive)}

Reactive dye was used in this research for investigation. These dyes form covalent bonds with cellulose. This chromophore in the dye molecule influences color in the fiber. These dyes are anionic and water soluble and have excellent colorfastness properties on cellulosic fabrics. They are ecofriendly, exploited monoazo systems for bright colors; coupling aniline to $\mathrm{H}$-acid gives the azo dye procion red, and anthraquinone dyes are applied to get bright blue colors. Figure $\mathbf{2}$ shows marinho sidercron, a reactive dye.

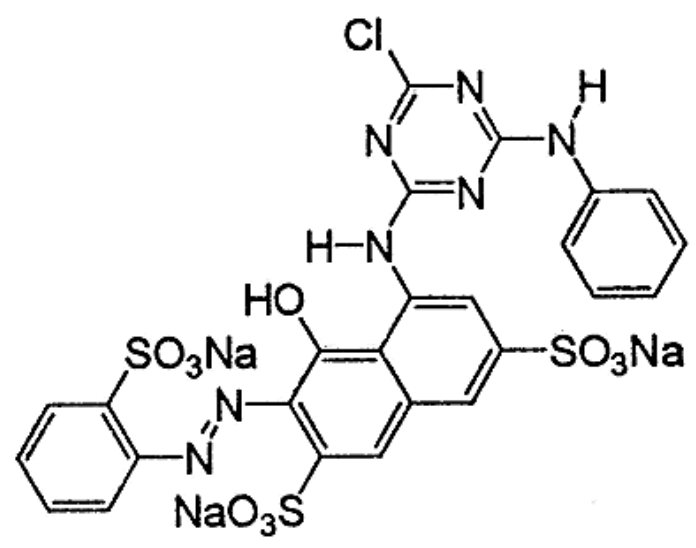

Figure 2 Moleclar structure of a reactive dye (marinho sidercron).

\section{Chemical type}

Wetting, sequestering, leveling, and fixing agents were used in this research for experimentation. These chemicals and auxiliaries were used for an efficient dyeing process. Table 2 shows the required chemicals and auxiliaries required for the research. 
Table 2 Chemicals applied in this experimentation.

\begin{tabular}{|c|c|c|c|c|}
\hline S.N & Formula & Chemical name & Medium & Function \\
\hline 1 & $\mathrm{C}_{20} \mathrm{H}_{37} \mathrm{NaO}_{7} \mathrm{~S}$ & Wetting agent & Base & to weaken surface tension \\
\hline 2 & $\mathrm{C}_{15} \mathrm{H}_{10} \mathrm{C}_{12} \mathrm{O}_{3}$ & Sequestering agent & Base & to reduce water hardness \\
\hline 3 & $\mathrm{C}_{17} \mathrm{H}_{25} \mathrm{OSO}_{3} \mathrm{Na}$ & Leveling agent & Base & to level the dyes \\
\hline 4 & $\left(\mathrm{NH}_{4}\right)_{2} \mathrm{~S}_{2} \mathrm{O}_{3}$ & Fixing agent & Base & for fixation of dyes \\
\hline 5 & $\mathrm{H}_{2} \mathrm{O}_{2}$ & Hydrogen peroxide & Acidic & $\begin{array}{l}\text { for oxidation, applied for oxygen } \\
\text { production and sodium carbonate }\end{array}$ \\
\hline 6 & $\mathrm{NaCl}$ & Sodium chloride & Base & to boost dye exhaustion \\
\hline 7 & $\mathrm{CH}_{3} \mathrm{COOH}$ & Acetic acid & Acidic & $\begin{array}{c}\text { to abolish superfluous dyes from fabric } \\
\text { surface }\end{array}$ \\
\hline
\end{tabular}

\section{Test method}

All the colorfastness properties of cellulosic fabrics were investigated as standard specified by AATCC and ASTM, as noted underneath the paper. Light fastness properties were experimented on as per the method specified by AATCC TM16.1 Standard. Wash fastness properties were experimented on as per the method specified by ASTM D435-42 Standard. Perspiration fastness properties were experimented on as per the method specified by AATCC TM15 Standard. Crocking fastness properties were experimented on as per the method specified by AATCC TM8 Standard.

\section{Color intensity and strength test in spectrophotometer}

Reflectance and absorption properties of textile materials were investigated using the Kubelka Monk Equation (K/S) to identify the color strength and intensity characteristics followed by Eqs. (1) - (2). In these two equations, color difference $(\Delta \mathrm{E})$ is measured by lightness values $(\Delta \mathrm{L})$, color saturation values, and color hue values. Color intensity or saturation values $(\Delta \mathrm{H})$ were also measured with the other properties of colors.

Measurement of color differences values;

$\Delta \mathrm{E} * \mathrm{ab}=[(\Delta \mathrm{L} *) 2+(\Delta \mathrm{a} *) 2+(\Delta \mathrm{b} *) 2] \frac{1}{2}$

Measurement of color saturation values;

$\Delta \mathrm{H} * \mathrm{ab}=[(\Delta \mathrm{E} * \mathrm{ab}) 2-(\Delta \mathrm{L} *) 2-(\Delta \mathrm{C} * \mathrm{ab}) 2]^{1 / 2}$

\section{Instruments used}

Light fastness properties of fabrics were investigated using a Light Fastness Tester TF421. Wash fastness properties of fabrics were investigated using a Launder Meter TF418. Perspiration fastness properties of fabrics were investigated using a Perspirometer TF416A. Crocking fastness properties of fabrics were investigated using a Crock Meter TF410. Color saturation properties were investigated using an "Agilent Cary 630 FTIR Instrument". This instrument could transfer infrared radiation to identify the color strength values and color intensity values. A Reflectance Spectrophotometer was also used to identify the color strength performances of textile materials. Cotton fabrics were dyed using a pad dye pad steam machine, Benninger, Germany. Fiber composition was tested by using a "TESTEX Fiber Content Analysis Tester TB300". A projection microscope, "Projectina DMM 2000", was used to check the cross section of the yarns.

\section{Cover factor measurement method}

Cover factor specifies the extent to which the area of a cloth is covered by yarns. It is the percentage of the area covered by the yarns to the total area of fabric. Cover factor also describes the compactness, solidity, and density of a fabric. The higher the cover factor, the less the penetration of dye particles; therefore, cover factor has a direct relationship with the color properties of fabrics. We know the weave factor for plain weave is 1 , weave factor for twill weave is 0.78 , and weave factor for satin weave is 0.68 . Cover factor can be calculated with the below Eq. (3). 
Cover factor measurement equation;

Fabric cover factor $=\left[\left\{\left(\frac{\text { EPI }}{\sqrt{\text { warp count }}}\right)+\left(\frac{\text { PPI }}{\sqrt{\text { weft count }}}\right)\right\}-\left[\frac{\left.\left\{\left(\frac{\text { EPI }}{\sqrt{\text { warp count }}}\right) \times\left(\frac{\text { PPI }}{\sqrt{\text { weft count }}}\right)\right\}\right]}{28}\right] \times\right.$ weave Factor

\section{Dyeing process}

Dye molecules react with fiber molecules to form covalent bonds between the dye reactive group and terminal $-\mathrm{OH}$ group of cellulosic fibers. Requisite chemicals, dye particles, and auxiliaries were taken in the required amounts, as mentioned in Table 2. Additional water, common salt, and dye were taken in a dye bath. During reactive dyeing, $\mathrm{pH}$ was maintained from 10 to 12 , and temperature was kept at $90{ }^{\circ} \mathrm{C}$ for 60 to $90 \mathrm{~min}$. The dyeing process took place in three states: the exhaustion of dye in the existence of electrolyte or dye immersion, fixation at the engagement of alkali, and washing off the unfixed dye particles from the fabric surface. When fiber was absorbed in the dye solution, an electrolyte was added to help with dye exhaustion. The following reactions occurred in the dye bath:

Cellulose- $\mathrm{OH}+\mathrm{HO}^{-} \Rightarrow$ Cellulose- $\mathrm{O}^{-}+\mathrm{H}_{2} \mathrm{O}$

Cellulose- $\mathrm{O}^{-}+$Dye- $\mathrm{Cl} \Rightarrow$ Cellulose-O-Dye $+\mathrm{Cl}^{-}$

Cellulose $-\mathrm{O}^{-}+$Dye- $-\mathrm{SO}_{2}-\mathrm{CH}=\mathrm{CH}_{2} \Rightarrow$ Dye $-\mathrm{SO}_{2}-\mathrm{CH}=\mathrm{CH}_{2}-\mathrm{O}-$ Cellulose

$(\mathrm{NCCl})_{3}+$ dye- $\mathrm{NH}_{2} \Rightarrow \mathrm{N}_{3} \mathrm{C}_{3} \mathrm{Cl}_{2}(\mathrm{NH}-$ dye $)+\mathrm{HCl}$

Subsequent dichlorotriazine attached to the fibers by dislocation of one of the two chloride groups;

$\mathrm{N}_{3} \mathrm{C}_{3} \mathrm{Cl}_{2}(\mathrm{NH}$-dye $)+\mathrm{HO}$-cellulose $\rightarrow \mathrm{N}_{3} \mathrm{C}_{3} \mathrm{Cl}(\mathrm{NH}$-dye $)(\mathrm{O}$-cellulose $)+\mathrm{HCl}$<smiles>[R]c1nc(Cl)nc(Cl)n1</smiles>

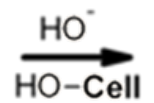<smiles>[R]S(=O)(=O)CCS(=O)(=O)O</smiles>

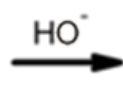<smiles>[R]c1nc(Cl)nc(O[AlH2])n1</smiles>

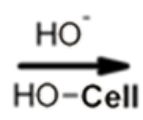<smiles>[R]S(=O)(=O)CCO[GeH3]</smiles>

Figure 3 Attachment of reactive dyes to fibres (Cell = cellulose, $\mathrm{R}=$ chromophore).

Figure 3 shows the attachment of reactive dyes to fibers. After dye fixation, a cold wash was given. This fixation procedure was directed to an alkaline dye cabinet. Like chloro-tri-azines, the functional group mixed with hydroxyl groups of fiber cellulose.

\section{Experimentation}

\section{Color strength and intensity test}

A Reflectance Spectrophotometer was used in this research to identify the color strength properties and the color intensity properties. The three samples were cut in 4 " $\times 2$ " for each size and put in the instrument. The instrument could hold the samples with its clamp, as shown in Figure 4. The clamp was adjustable in order to place the samples at the right place. This instrument used a tungsten light source to take the color values with its flashing system. 


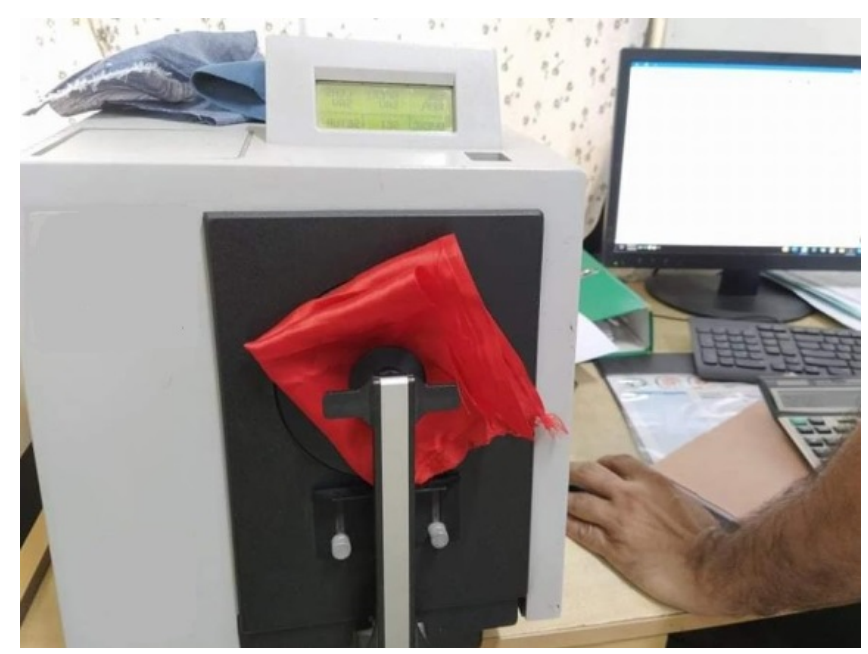

Figure 4 Checking the color values with reflectance spectrophotometer.

Color strength $(\mathrm{K} / \mathrm{S})$ and intensity were measured using wave numbers from 330 to $900 \mathrm{~nm}$ surrounded by the detectable range. Further color values, such as $\mathrm{L}^{*}, \mathrm{a}^{*}, \mathrm{~b}^{*}, \mathrm{C}^{*}$, and $\mathrm{h}^{*}$, were also obtained.

\section{Colorfastness test}

Light fastness properties of fabrics were investigated using a Light Fastness Tester TF421 as per the method specified by AATCC TM16.1 Standard. Wash fastness properties of fabrics were investigated using a Launder Meter TF418 as per the method specified by ASTM D435-42 Standard. Perspiration fastness properties of fabrics were investigated using a Perspirometer TF416A as per the method specified by AATCC TM15 Standard. Crocking fastness properties of fabrics were investigated using a Crock Meter TF410 as per the method specified by AATCC TM8 Standard.

\section{Cover factor measurement}

Cover factor specifies the extent to which the area of a cloth is covered by the yarns. It is the percentage of the area covered by yarns to the total area of fabric. Higher cover factor expresses more compactness of fabrics, so dye penetration would be difficult for fabrics with higher cover factors. The lower the cover factor, the more the penetration of dye particles, so cover factor has a direct relationship with the color properties of fabrics. Cover factor was measured with Eq. (4), as stated above. We know the weave factor for plain weave is 1 , weave factor for twill weave is 0.78 , and weave factor for satin weave is 0.68 .

Cover factor measurement equation;

Fabric cover factor $=\left[\left\{\left(\frac{\text { EPI }}{\sqrt{\text { warp count }}}\right)+\left(\frac{\text { PPI }}{\sqrt{\text { weft count }}}\right)\right\}-\left[\left\{\frac{\left(\frac{\text { EPI }}{\sqrt{\text { warp count }}}\right) \times\left(\frac{\text { PPI }}{\sqrt{\text { weft count }}}\right)}{28}\right]\right] \times\right.$ weave Factor

\section{Cover factor measurement of sample $A$}

It is seen from Table 1 that the construction of fabric A was $\frac{20 \times 16}{110 \times 58}$. Here, warp yarn count was $20 \mathrm{Ne}$, weft yarn count was $16 \mathrm{Ne}$, EPI was 110 , and PPI was 58. Weave factor for plain weave was 1. Therefore, the cover factor of the fabric was measured with Eq. (3), as shown below; 


$$
\begin{aligned}
& {\left[\left\{\left(\frac{\text { EPI }}{\sqrt{\text { warp count }}}\right)+\left(\frac{\text { PPI }}{\sqrt{\text { weft count }}}\right)\right\}-\left[\frac{\left(\left(\frac{\text { EPI }}{\sqrt{\text { warp count }}}\right) \times\left(\frac{\text { PPI }}{\sqrt{\text { weft count }}}\right)\right\}}{28}\right] \times\right. \text { weave Factor }} \\
& {\left[\left\{\left(\frac{110}{\sqrt{20 \mathrm{Ne}}}\right)+\left(\frac{58}{\sqrt{16 \mathrm{Ne}}}\right)\right\}-\left[\frac{\left\{\left(\frac{110}{\sqrt{20 \mathrm{Ne}}}\right) \times\left(\frac{58}{\sqrt{16 \mathrm{Ne}}}\right)\right\}}{28}\right]\right] \times 1} \\
& {\left[\left\{\left(\frac{110}{\sqrt{20}}\right)+\left(\frac{58}{\sqrt{16}}\right)\right\}-\left[\frac{\left\{\left(\frac{110}{\sqrt{20}}\right) \times\left(\frac{58}{\sqrt{16}}\right)\right\}}{28}\right]\right] \times 1} \\
& \begin{array}{l}
{\left[\left\{\left(\frac{110}{4.4721}\right)+\left(\frac{58}{4}\right)\right\}-\left[\frac{\left\{\left(\frac{110}{4.4721}\right) \times\left(\frac{58}{4}\right)\right\}}{28}\right]\right] \times 1} \\
{\left[\{24.5969+14.5\}-\left[\frac{\{24.5969 \times 14.5\}}{28}\right]\right] \times 1}
\end{array} \\
& {\left[39.0969-\left[\frac{356.6551}{28}\right]\right] \times 1} \\
& {[39.0969-12.7377] \times 1} \\
& 26.3592 \times 1 \\
& 26.3592
\end{aligned}
$$

Hence, the cover factor for sample A was 26.3592 .

Following the same method, calculation for sample B and sample C were conducted with Eq. (3), as stated above, and the results are shown in Table 5.

\section{Microscopic test}

Yarns were removed from the three fabrics and observed through a light microscope, using glycerin as a mounting liquid.

\section{FTIR test}

Infrared radiation was passed through the three types of samples using an "Agilent Cary 630 FTIR Instrument" to detect the color absorbency characteristics. IR radiation was used to detect the intensity of the dye stuffs inside the cellulosic fabrics. IR rays could detect the reflectance values. Lower peak values confirmed least depth shades.

\section{Result and discussion}

\section{Color strength and color intensity values}

Using a reflectance spectrophotometer, the color strength values and the color intensity values were obtained and are positioned in Table 3. This instrument used the Kubelka Monk Equation, scanned the samples with a tungsten light source, and obtained these values of color strength (K/S) and intensity. The maximum values of K/S specify the best intense color, while the lightness values are lower. On the contrary, the lowermost values of K/S specify the lower intense color with the maximum lightness (L) values. 
Table 3 Color strength and intensity values with hue, value, and chroma.

\begin{tabular}{ccccccc}
\hline Sample Type & $\mathbf{K} / \mathbf{S}$ & $\mathbf{L}$ & $\mathbf{a} *$ & $\mathbf{b}^{*}$ & $\mathbf{c}^{*}$ & $\mathbf{h}^{*}$ \\
\hline Plain weave $\left(\frac{\mathbf{1}}{\mathbf{1}}\right)$ fabric & 3.77 & 39.73 & 0.33 & 1.23 & -1.27 & 82.89 \\
Twill weave $\left(\frac{\mathbf{2}}{\mathbf{1}}\right)$ fabric & 3.41 & 43.27 & -2.21 & 3.63 & 4.29 & 78.99 \\
Satin weave $\left(\frac{\mathbf{4}}{\mathbf{1}}\right)$ fabric & 3.29 & 47.58 & 3.99 & -21.39 & 24.38 & 77.11 \\
\hline
\end{tabular}

It is seen from Table 3 that plain weave fabric had the highest color strength value $(\mathrm{K} / \mathrm{S})$ of 3.77 ; alternatively, stain weave fabric had the lowest color strength value of 3.29. Plain weave fabric showed the lowest lightness (L) value of 39.73, and satin exposed the best lightness value of 47.58. Maximum shade depth (h) was obtained for plain weave fabric, but satin had the least values of $h$. Twill weave fabric specified a compromised character in all cases of experimentation. In this chart, $\mathrm{a}^{*}, \mathrm{~b}^{*}$, and $\mathrm{c}^{*}$ were expressed just as positive and negative values. These negative values expressed greenish and bluish shades, whereas positive values specified red and yellow.

\section{Colorfastness observation}

Colorfastness values of plain, twill, and satin weave fabrics were investigated using gray scale and the values are positioned in Table 4. Plain weave fabric exposed the best colorfastness properties at all the stages, both in Acidic/Alkaline medium or in Dry/Wet condition. On the other hand, satin weave fabric exposed the poorest colorfastness properties. Twill weave fabric exposed compromised values in between plain and twill weave fabrics.

\section{Wash fastness}

Table 4 exposed the best wash fastness value of 3.5 for plain weave fabric. The lowest wash fastness value of 2.5 was exposed for satin weave fabric. Twill weave fabric had a compromised value of 3 , in between plain weave and twill weave fabric.

Table 4 Color fastness values of plain, twill, and satin fabrics.

\begin{tabular}{|c|c|c|c|c|c|c|}
\hline \multirow{2}{*}{ Fabric dyed with } & \multirow{2}{*}{$\begin{array}{c}\text { Wash } \\
\text { Fastness }\end{array}$} & \multirow{2}{*}{$\begin{array}{c}\text { Light } \\
\text { Fastness }\end{array}$} & \multicolumn{2}{|c|}{$\begin{array}{c}\text { Perspiration } \\
\text { Fastness }\end{array}$} & \multicolumn{2}{|c|}{ Rubbing Fastness } \\
\hline & & & Acidic & Alkaline & Dry & Wet \\
\hline Plain weave $\left(\frac{1}{1}\right)$ fabric & $3-4$ & 4 & $3-4$ & 3 & 3 & $2-3$ \\
\hline Twill weave $\left(\frac{2}{1}\right)$ fabric & 3 & $3-4$ & 3 & $2-3$ & $2-3$ & $2-3$ \\
\hline Satin weave $\left(\frac{4}{1}\right)$ fabric & $2-3$ & 3 & 3 & 2 & $2-3$ & 2 \\
\hline
\end{tabular}

\section{Light fastness}

Table 4 shows the best light fastness value of 4 for plain weave fabric. The lowest light fastness value of 3 was exposed for satin weave fabric. Twill weave fabric had a compromised value of 3.5, in between plain weave and twill weave fabric.

\section{Perspiration fastness}

Table 4 shows the best perspiration fastness values of 3.5 (acidic)/3 (alkaline) for plain weave fabric. The lowest perspiration fastness values of 3 (acidic)/2 (alkaline) were exposed for satin weave fabric. Twill weave fabric had compromised values of 3 (acidic)/2.5 (alkaline), in between plain weave and twill weave fabric. 


\section{Rubbing fastness}

Table 4 shows the best rubbing fastness values of 3 (dry)/2.5 (wet) for plain weave fabric. The lowest rubbing fastness values of 2.5 (dry)/2 (wet) were exposed for satin weave fabric. Twill weave fabric had compromised values of 2.5 (dry)/2.5 (wet), in between plain weave and twill weave fabric.

Cover factor observation

It is seen from Table 5 that the plain weave fabric had the highest cover factor of 26.3592 . On the other hand, satin weave fabric had the lowest cover factor of 18.0069 .

Table 5 Cover factor comparison of three types of woven fabrics.

\begin{tabular}{cccccc}
\hline S.N & Construction & Weave & $\begin{array}{c}\text { Warp cover } \\
\text { factor }\end{array}$ & $\begin{array}{c}\text { Weft cover } \\
\text { factor }\end{array}$ & $\begin{array}{c}\text { Total cover } \\
\text { factor }\end{array}$ \\
\hline $\mathbf{A}$ & $\frac{20 \times 16}{110 \times 58}$ & Plain $\left(\frac{1}{1}\right)$ & 24.59 & 14.50 & 26.3592 \\
B & $\frac{20 \times 16}{110 \times 60}$ & Twill $\left(\frac{2}{1}\right)$ & 24.59 & 13.17 & 20.6076 \\
C & $\frac{20 \times 16}{110 \times 62}$ & Satin $\left(\frac{4}{1}\right)$ & 24.59 & 15.50 & 18.0069 \\
\hline
\end{tabular}

If the cover factor is high, then the compactness of fabric is also high, so dye penetration would be less for fabrics with higher cover factors. If the cover factor is lower, then the compactness of fabric is also lower; this means the fabric would be loosely woven, so dye penetration would be high for fabrics with lower cover factors. Twill and satin weave fabrics are bulky. They have sufficient looseness in their structures compared to plain weave. Therefore, twill and satin weave fabrics can absorb more dye particles compared to plain weave fabic. Plain weave fabric absorbs fewer dye particles compared to twill and satin weave. While washing or crocking, twill and satin weave fabric release more dye particles compared to plain weave fabric. Plain weave fabric absorbs fewer dye particles, so they release fewer dye particles. However, satin and twill weave fabric absorb more dye particles, so they release more dye particles. Plain weave fabric releases fewer dye particles; therefore its colorfastness properties are always better than twill and satin weave fabrics.

\section{Microscopic observation}

A light microscope was used to inspect the yarn cross sectional views. Firstly, the yarns were removed from fabric and placed in this instrument to inspect them for assessment. Figure $\mathbf{5}$ shows the microscopic view of the yarn from plain weave $\left(\frac{1}{1}\right)$ fabric, and Figure 6 shows the microscopic view of the yarn from twill weave $\left(\frac{2}{1}\right)$ fabric. It is clearly apparent from these figures that the cross sectional view of the yarn of plain weave has a tight shape, with its compact weave structure of interlacement at the ratio of 1 up and 1 down. On the other hand, the cross sectional view of the yarn of twill weave has a hairiness and bulky shape, with its loose weave structure of interlacement at the ratio of 2 up and 1 down.

The bulky weave structure of twill weave fabric has sufficient empty space in its structure at open field and free field, so it can absorb more dye particles compared to plain weave. On the other hand, due to having a compact structure in plain weave fabric, it does not have enough empty spaces at its open field and free field. Therefore, plain weave fabric absorbs fewer dye particles compared to twill weave. While washing or crocking, twill weave releases more dye particles compared to plain weave fabric. Plain weave fabric absorbs fewer dye particles, so they release fewer dye particles. However, twill weave fabric absorbs more dye particles, so they release more dye particles. Since plain weave fabric release fewer dye particles, therefore, their colorfastness properties are always better than twill weave fabrics. Satin weave fabrics also show the same characteristics as twill weave fabrics. Microscopic views help to observe this phenomena. 


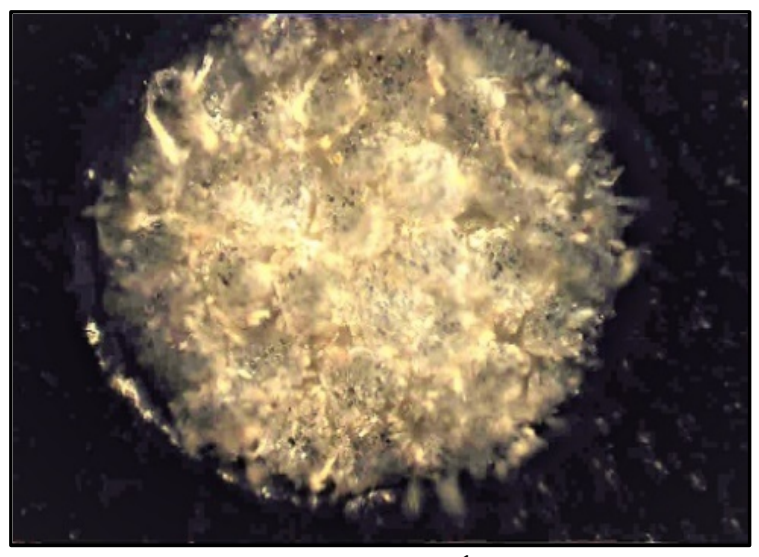

Figure 5 Microscopic view of the yarn from plain weave $\left(\frac{\mathbf{1}}{\mathbf{1}}\right)$ fabric (compact shape).

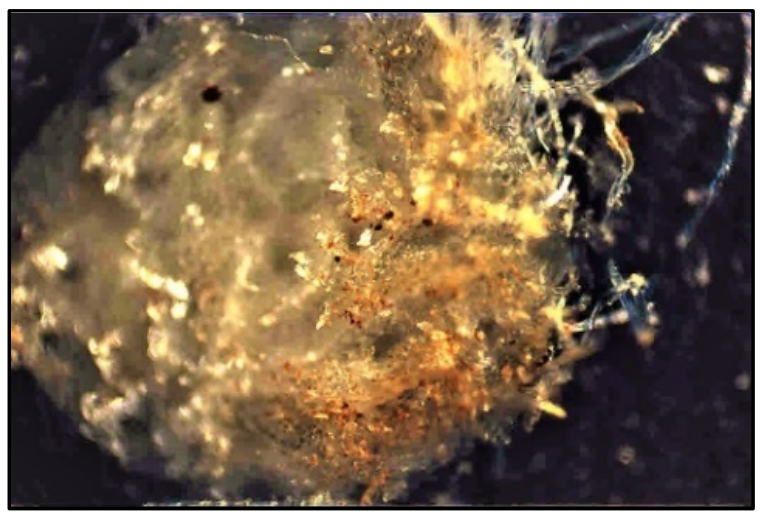

Figure 6 Microscopic view of the yarn from twill weave $\left(\frac{2}{1}\right)$ fabric (hairiness shape).

\section{FTIR observation}

Using a Fourier Transform Infrared spectroscopy (FTIR) instrument, color strength, intensity, color absorbency, and colorfastness properties were investigated with its IR observeble spectrum. IR rays specify the color intensity and absorbency to the substrate. IR rays passed a few microns through the fabrics, and the peak values were spotted. The more the peak values are, the higher the color strength, intensity, and absorbency are. The most intense color exhibits best colorfastness properties due to higher intensity and strength. In the FTIR surveillance area covered by the IR, spectroscopy was from 650 to 4000 wave numbers. This instrument could measure the spectroscopy within the visible spectral province with the maximum IR peak values. It is seen, from Table 6, that plain weave fabric exposed the highest peak values amongst all the samples.

Table 6 Highest peak values of FTIR illustration.

\begin{tabular}{ccc}
\hline S.N & Fabric type & Highest peak values \\
\hline A & Plain weave $\left(\frac{1}{1}\right)$ fabric & $3691.21 \mathrm{~cm}^{-1}$ \\
B & Twill weave $\left(\frac{2}{1}\right)$ fabric & $3479.21 \mathrm{~cm}^{-1}$ \\
C & Satin weave $\left(\frac{4}{1}\right)$ fabric & $3438.23 \mathrm{~cm}^{-1}$ \\
\hline
\end{tabular}




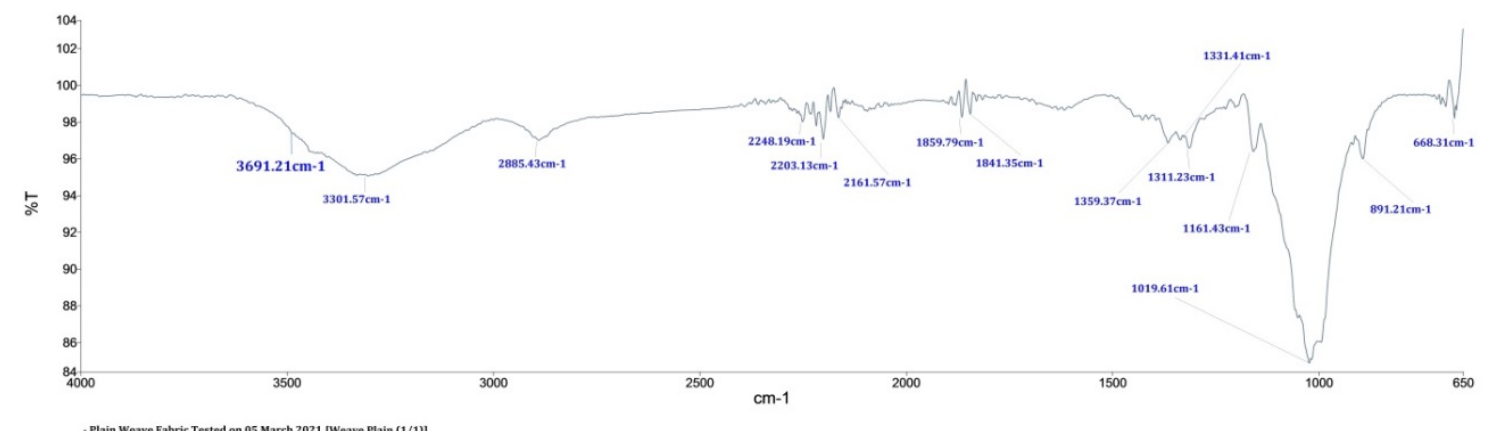

Figure 7 Plain weave fabric illustrated a maximum peak value of $3691.21 \mathrm{~cm}^{-1}$.

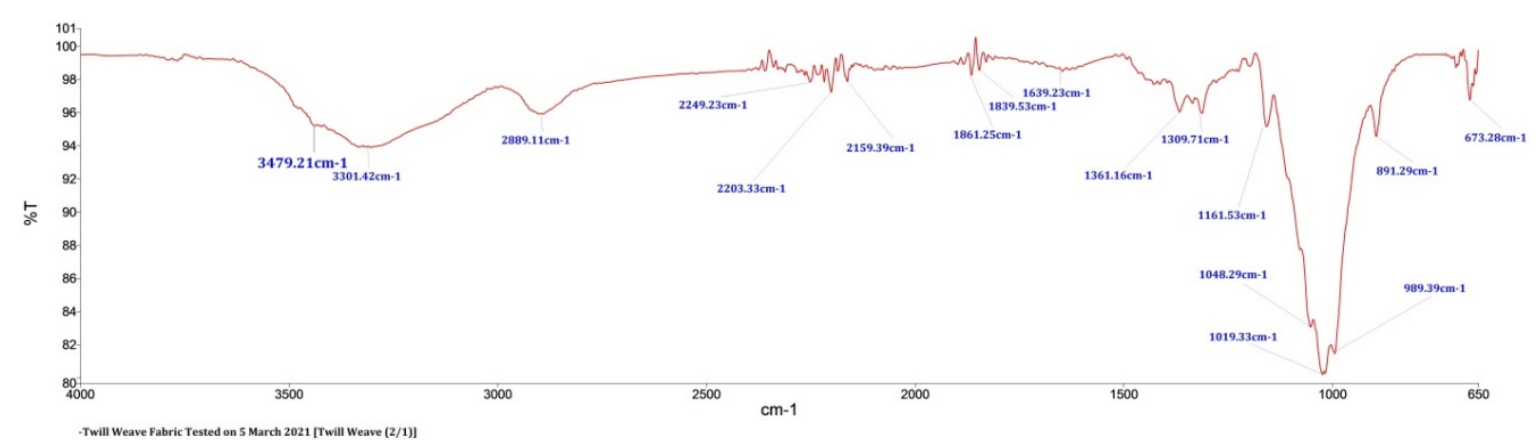

Figure 8 Twill weave fabric illustrated a maximum peak value of $3479.21 \mathrm{~cm}^{-1}$.

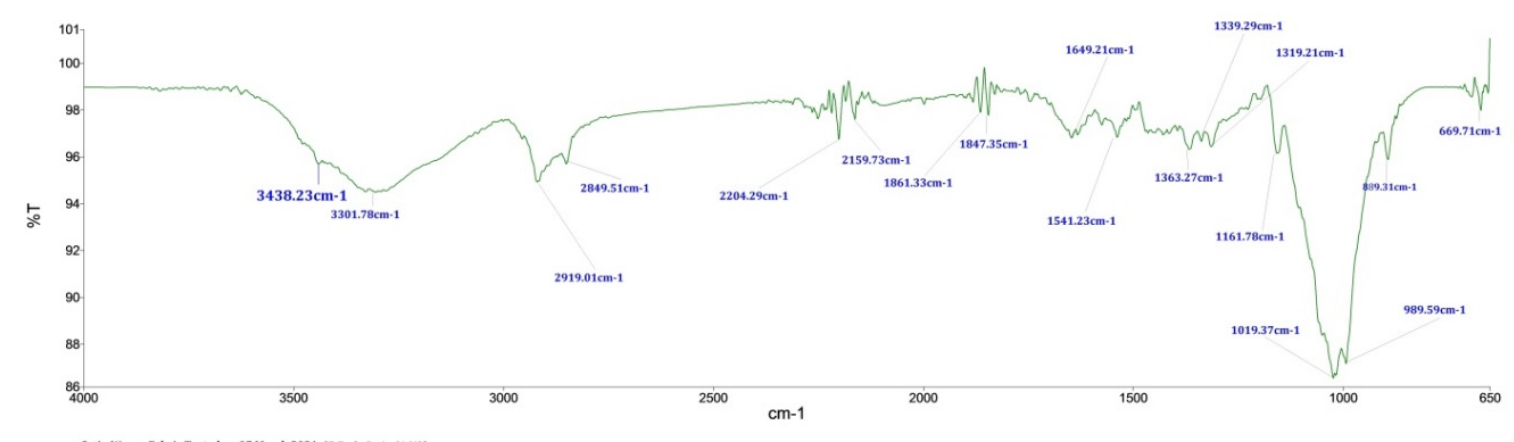

Figure 9 Satin weave fabric illustrated a maximum peak value of $3438.23 \mathrm{~cm}^{-1}$.

Plain weave fabric illustrated the maximum peak value of $3691.21 \mathrm{~cm}^{-1}$, shown in Figure 7. The peak value detected the existence of colorant in the noticeable spectral area and could sense the chromophore present in the dyestuffs. The maximum peak value of $3691.21 \mathrm{~cm}^{-1}$ authorizes the best colorfastness properties. The lowest peak value of $3438.23 \mathrm{~cm}^{-1}$ authorizes the poorest colorfastness property, that was shown in Figure 9, by satin fabric. Twill weave fabric exposed a compromised colorfastness property, with its peak value of $3479.21 \mathrm{~cm}^{-1}$, shown in Figure 8. This is why the best colorfastness properties were attained sequentially in plain weave fabric $\left(3691.21 \mathrm{~cm}^{-1}\right)$, then in twill weave fabric $\left(3479.21 \mathrm{~cm}^{-1}\right)$ and, last, in satin weave fabric $\left(3438.23 \mathrm{~cm}^{-1}\right)$. 


\section{Conclusions}

The colorfastness properties, color strength properties, and color intensity characteristics of reactive dyes on plain, twill, and satin woven cellulosic fabrics were investigated. The investigation proved that the plain weave fabric had the best colorfastness properties compared to twill weave and satin weave fabrics. Firstly, the amount of dyestuffs taken up by twill weave and satin weave fabrics was more than that of plain weave, since plain weave fabric had more compactness in its structure, due to its interlacement structure. On the other hand, twill weave and satin weave had bulkiness in their structures, so they released more dyestuffs while washing, crocking, or during other colorfastness tests. The amount of chromophore existing in the plain weave fabric was more, since its interlacement structure was much more rigid, which we identified from FTIR illustration.

\section{References}

[1] A Rehman, A Ahmad, A Hameed, S Kiran and T Farooq. Green dyeing of modified cotton fabric with Acalypha wilkesiana leave extracts. Sustain. Chem. Pharm. 2021; 21, 100432.

[2] DN Zaghloul, TA Elmaaty, K Nakamura, I Tabata, T Hori and K Hirogaki. Influence of additive organic base on dyeing of cotton fabric under supercritical carbon dioxide using fluorotriazine reactive disperse dye and investigation of optimal dyeing conditions. J. Supercrit. Fluid. 2021; 174, 105243.

[3] UH Siddiqua, S Ali, S Muzaffar, Z Subhani, M Iqbal, H Daud, DN Iqbal and A Nazir. Heterofunctional azo reactive dyes applied on cellulosic fabric and dyeing conditions optimization to enhance the dyeing properties. J. Eng. Fibers Fabrics 2021; 16, 1-12.

[4] L Pei, Y Luo, MA Saleem and J Wang. Sustainable pilot scale reactive dyeing based on silicone oil for improving dye fixation and reducing discharges. J. Cleaner Prod. 2021; 279, 123831.

[5] S Islam, SMM Alam and S Akter. Influence of thermal conduction on the stretching behavior of core spandex cellulosic fabrics. Mater. Today Proc. 2021; 38, 2563-71.

[6] S Islam, SMM Alam and S Akter. 2021. Identifying the amount of heat flux and thermal conduction through fabrics with appropriate heat equation. Comput. Eng. Phys. Model. 4, 53-67.

[7] IWK Suryawan, G Prajati, AS Afifah and MR Apritama. NH3-N and COD reduction in Endek (Balinese textile) wastewater by activated sludge under different DO condition with ozone pretreatment. Walailak J. Sci. \& Tech. 2021; 18, 9127.

[8] A Rehman, K Iqbal, F Azam, F Safdar, M Ashraf, HS Maqsood and A Basit. To enhance the dyeability of cotton fiber with the application of reactive dyes by using chitosan. J. Textil. Inst. 2020; 112, 1208-12

[9] M Wang, C Guo, C Li and T Zhao. Design of novel reactive dyes containing cationic groups: Mechanism and application for environmentally friendly cotton dyeing. Fibers Polym. 2020; 21, 2848-60.

[10] S Islam, SMM Alam and S Akter. Investigation of the colorfastness properties of natural dyes on cotton fabrics. Fibers Textil. 2020; 27, 58-68.

[11] S Islam, SMM Alam and S Ahmed. Attaining optimum values of colourfastness properties of sustainable dyes on cotton fabrics. Fibres Textil. E. Eur. 2020; 28, 110-7.

[12] S Islam, SMM Alam and S Akter. Mathematical investigation of the thermal conductivity of fabrics using thermal equation. Mater. Today Proc. 2021; 46, 413-24.

[13] N Nadeem, M Zahid, A Tabasum, A Mansha, A Jilani, IA Bhatti and HN Bhatti. Degradation of reactive dye using heterogeneous photo-Fenton catalysts: $\mathrm{ZnFe}_{2} \mathrm{O}_{4}$ and $\mathrm{GO}-\mathrm{ZnFe}_{2} \mathrm{O}_{4}$ composite. Mater. Res. Express 2020; 7, 015519.

[14] F An, K Fang, X Liu, C Li, Y Liang and H Liu. Rheological properties of carboxymethyl hydroxypropyl cellulose and its application in high quality reactive dye inkjet printing on wool fabrics. Int. J. Biol. Macromol. 2020; 164, 4173-82.

[15] S Wang, J Liu, L Sun, H Wang, P Zhu and C Dong. Preparation of flame-retardant/dyed cotton fabrics: Flame retardancy, dyeing performance and flame retardant/dyed mechanism. Cellulose 2020; 27, 10425-40.

[16] F Parvin, S Islam, Z Urmy and S Ahmed. A study on the textile materials applied in human medical treatment. Eur. J. Physiother. Rehabil. Stud. 2020; 1, 56-80.

[17] W Dechapanya, K Intawong and S Jawjit. Synthesis and characterization of TTIP-Al films and Fe3+/TTIP-Al films to be used in photocatalytic oxidation under visible light. Walailak J. Sci. \& Tech. 2021; 18, 6551. 
[18] M Chairat. Thermodynamics study of lac dyeing of silk yarn coated with chitosan. Walailak J. Sci. \& Tech. 2009; 6, 93-107.

[19] A Milašius and V Milašius. New representation of the fabric weave factor. Fibres Textil. E. Eur. 2008; 16, 48-51.

[20] D Shu, K Fang, X Liu, Y Cai, F An, G Qu and Y Liang. Cleaner pad-steam dyeing technology for cotton fabrics with excellent utilization of reactive dye. J. Cleaner Prod. 2009; 241, 118370.

[21] S Islam. Attaining optimum strength of cotton-spandex woven fabric by apposite heat-setting temperature. J. Inst. Eng. (India) C 2009; 100, 601-6.

[22] L Liu, B Mu, W Li and Y Yang. Cost-effective reactive dyeing using spent cooking oil for minimal discharge of dyes and salts. J. Cleaner Prod. 2009; 227, 1023-34.

[23] L Liu, B Mu, W Li and Y Yang. Sustainable emulsion system based on spent cooking oil for pilotscale reactive dyeing with minimal discharges. ACS Sustain. Chem. Eng. 2019; 7, 13698-707.

[24] SMS Islam, M Alam and S Akter. Identifying the values of whiteness index, strength and weight of cotton spandex woven fabric in peroxide bleaching of different concentration. Fibers Textil. 2019; 4, 96-107.

[25] S Islam, SMM Alam and S Akter. The consequences of temperature on the shrinkage properties of cotton spandex woven fabric. J. Textil. Polymer. 2019; 7, 25-29.

[26] S Islam, S Ahmed, M Arifuzzaman, AKMS Islam and S Akter. Relationship in between strength and polyester content percentage of cotton polyester blended woven fabrics. Int. J. Clothing Sci. $2019 ; 6,1-6$.

[27] S Islam, SMM Alam and S Akter. Identifying a suitable heat setting temperature to optimize the elastic performances of cotton spandex woven fabric. Res. J. Textil. Apparel 2018; 22, 260-70.

[28] M Sadeghi-Kiakhani, AR Tehrani-Bagha and S Safapour. Enhanced anti-microbial, anti-creasing and dye absorption properties of cotton fabric treated with chitosan-cyanuric chloride hybrid. Cellulose 2018; 25, 883-93.

[29] S Islam and SMM Alam. Investigation of the acoustic properties of needle punched nonwoven produced of blend with sustainable fibers. Int. J. Clothing Sci. Tech. 2018; 30, 444-58.

[30] D Shu, K Fang, X Liu, Y Cai, X Zhang and J Zhang. Cleaner coloration of cotton fabric with reactive dyes using a pad-batch-steam dyeing process. J. Cleaner Prod. 2018; 196, 935-42.

[31] M Zahid, IA Bhatti, S Adeel and S Saba. Modification of cotton fabric for textile dyeing: Industrial mercerization versus gamma irradiation. J. Textil. Inst. 2017; 108, 287-92.

[32] UH Siddiqua, S Ali, M Iqbal and T Hussain. Relationship between structure and dyeing properties of reactive dyes for cotton dyeing. J. Mole. Liq. 2017; 241, 839-44.

[33] MAR Bhuiyan, A Shaid, MM Bashar and P Sarkar. Investigation on dyeing performance of basic and reactive dyes concerning jute fiber dyeing. J. Nat. Fibers 2016; 13, 492-501.

[34] KH Prabhu and AS Bhute. Plant based natural dyes and mordants: A review. J. Nat. Prod. Plant Resour. 2012; 2, 649-64.

[35] D Stawski and J Szumilewicz. Formation of interpolymer complexes on polypropylene textiles via layer-by-layer modification as revealed by FTIR method. Walailak J. Sci. \& Tech. 2012; 9, 165-71.

[36] AS Belal. Understanding textiles for a merchandiser. BMN3 Foundation, Dhaka, 2009. 